\title{
أدب الأطفال .. وتحديات إشكاليات التجديد
}

أ. إيهاب القسطاوي

\section{كاتب صحفي}

متخصص في أدب الأطفال

باتت و اضحة جدًا آثار الأزمة الوخيمة التي تلقي بظلالها على أدب الأطفال، سواء من حيث المحتوى النصي أو تقنية العرض والأسلوب، والتي آلت إليها أوضاع المحتوى المخصّص للأطفال في عالمنا العربي، و إنه لمن المؤسف جدًا أن جميع الدول العربية لم تتمكن على مدار سنواتٍ من إنتاج قصة للأطفال ترتقي إلى مصاف العالمية، لذا فقد أصبحنا في حاجة مُلحّة الى مر اجعة ما نقدّمه لأطفالنا، للوقوف بشكلٍ علمي دقيق على أسباب هذه الأزمة، وكيفية تداركها، و العمل بشكلٍ جدّي لإنتاج أعمال ملهمة ومُحفّة للأطفال، من خلال ابتكار محتوى يحاكى البيئة المحلية، نستطيع من خلاله أن نحلّق بروح الأطفال البريئة، و نتماشى مع فطرتهم الإنسانية الخالصة، ونحمل إليهم قيمًا وسلوكيات نودّ حقًا أن نعزّز ها بهم، والاستعاضة عن التكر ار و العادي و التقليد المبتذل، بالإبداع الحقيقي، وخصوصًا ونحن في بداية مرحلة جديدة من التو اجد بكثافة في قلب القارة السمر اء التي تُعد بمثابة عمق ثقافي

لنا، ومما يؤ هلنا ليكون لدينا فرصة ذهبية للوصول للعالمية بالمحتوى المخصّص للأطفال. والحقيقة إن أدب الأطفال في العصر الحالي، يواجه العديد من التحديات التي قد تكمن في مُجملها في إثناليات التجديد، وآليات التغير والتغيير، وتشابك المفاهيم و الخصائص التي تحملها، مع الطفرة التكنولوجية الهائلة، والتقنيات الحديثة المذهلة بكل ما تحمله من رؤى و أفكار مغايرة، مما قد أسهم وبشكلٍ كبيرٍ على تقوقعه وانكفائه على ذاته، لتكون المُحصِّلة النهائية، منتجًا مكررًا ورتيبًا، لا يروى ظمأ خصوبة خيال الأطفال، ولا يجيب على تساؤلاتهم المحقّة التي تروداهم، مما قلّل من توزانه الدفاعي، باعتباره الوعاء والحاضنة الحقيقية للأطفال من حيث غَرْس بذور الوعى، والقيم الأخلاقية من عدمها، مما دفع بخلْق حالة من العزوف عنه، لينتحى جانبًا، ويمهذ الطريق أمام هذه التكنولوجيا؛ نظرًا لسهولة تداولها نسبيًا، ولا خيار أمامه سوى أن ينظر في أساس التقدم و التطور الذى يحيط به من كل اتجاه، ويمضي في رَكْب الحداثة، بكل ما تحمله من تقدم وتطور مفاجئ، وأن يغيّر مفهومه ليواكب هذه التحديات التي تنمى لطفل هذا العصر هر 


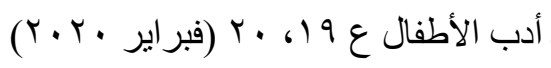
أدب الأطفال وتحديات إثكاليات التجديد

الفضول، وتشعل في رأسه أسئلة جديدة تجعل عقله يبحث عن الإجابات المقنعة، خصوصًا بعدما زاد الحديث في الآوانة الأخيرة، عن وضع أدب الأطفال ودوره في مواجهة هذه التقنيات الحديثة المذهلة بكل ما تحمله من رؤى و أفكارٍ مغايرة وبمستقبله و أهدافه و التحديات

التي تواجهاه، و الوسائل التي يمكن أن بستعين بها لمواجهة هذه التحديات و التغلب عليها. لذلك لقد حان الوقت لمبدعى أدب الطفل في مصر وعالمنا العربى، ومؤسساتهم الممتدة من الخليج العربي للمحيط الأطلسي، و لاسيما المؤسسات الثقافية التي تتباهى بعض الدول النفطية العربية من خلالها بإطلاق آلاف النسخ من المسابقات المخصصة للأطفال و الناثنئة في مر احلهم العمرية المختلفة، ولمبدعى أدب الطفل، باثتر اطات عفا عليها الزمن، ملهن للتجرؤ على اقتحام الكابو هات و المحرمات المحكومة دائًا بسلسلة من المصدات و المحرمات بوزاع منظومة القيم الاجتماعية والأخلاقية كالعيب و الحر ام، بجسارة. وَقَّْ أَجد لزامًا عليّ في هذا الصدد أن أقتبس فقرة مهمة من مقال الدكتورة نوال السعداوي، المنشور في موقع جريدة "إيلاف" الإلكترونية في • 1 يونيو 10 . ب بعنوان "أسئلة الأطفال المحرمة وتجديد الفكر الدينى"، حيث قالت: "تتطلع الطفلة أو الطفل بانبهار الى أضو اء النجوم وتسأل: مين خلق النجوم؟ ويردّ الكبار : ربنا، وعلى الفور تسأل الطفلة أو الطفل: ومين خلق ربنا؟ سؤال بديهى يَرِد لجميع الأطفال، ثم يطويه النسيان ضمن أسئلة يتم تحريمها؛ خوفًا من السلطة في البيت و المدرسة، يؤدى الخوف الى النسيان، حماية للطفل أو الطفلة من القلق وانتظار الحرق بالنار أو الإصـابة بالصرع". لذا فإن مهمة تحرير عقول الأطفال من الخوف من النقد باتت المعركة الحقيقية لكُتاب أدب الأطفال، بأن يخترقو ابوعي وشجاعة ومسؤلية عالم "القارى الصغير" انطلافًًا من اللغة التي يفهمها، لتهيئة بيئة من الوعى والمعرفة في وجدانه، وإلا سيصبحون نسخًا مُبتذلة سخيفة لأسلافهم الذين عملوا على مدار عقودٍ من الزمن على اجنزاز الوعي من عقول أطفالنا بسطحية وبشاعة ما يكتبون، أَوْ أن يتركوا المجال لمبدعين حقيقيين بزخٍ ثقافي مبي وفني و إبداعي. 